\title{
Characterization of Pig and Poultry Origin Escherichia coli for Beta-lactamase Type Antimicrobial Resistance
}

\author{
Ranjan Mahadewaswami ${ }^{1}$, Rahul Kolhe ${ }^{1 *}$, Chandrakant Bhong ${ }^{1}$, Prashant Mhase ${ }^{2}$, Sameer Jadhav ${ }^{3}$, \\ Vijaysinh Lonkar ${ }^{4}$ and Sujata Bhave ${ }^{1}$ \\ ${ }^{1}$ Department of Veterinary Public Health, KNP College of Veterinary Science, Shirwal, District Satara, Maharashtra Animal \\ E Fishery Sciences University, Nagpur, INDIA \\ ${ }^{2}$ Department of Veterinary Microbiology, KNP College of Veterinary Science, Shirwal, District Satara, Maharashtra Animal \& \\ Fishery Sciences University, Nagpur, INDIA \\ ${ }^{3}$ Department of Veterinary Biochemistry, KNP College of Veterinary Science, Shirwal, District Satara, Maharashtra Animal \\ \& Fishery Sciences University, Nagpur, INDIA \\ ${ }^{4}$ Department of Poultry Science, Nagpur Veterinary College, Seminary Hills Nagpur, Maharashtra Animal \& Fishery Sciences \\ University, Nagpur, INDIA
}

*Corresponding author: RP Kolhe; E-mail:dr_kolherahul@rediffmail.com

Received: 21 May, 2021

Revised: 23 June, 2021

Accepted: 08 July, 2021

\begin{abstract}
A study was conducted to know the prevalence of antimicrobial resistant Escherichia coli in fecal samples of pigs and broiler chicken. Fecal swabs were collected from apparently healthy animals and birds using sterile swabs. From a flock of 6000 birds, and a herd of 550 pigs, 50 samples each, were collected randomly. E. coli was isolated from all the broiler chicken samples, and $82 \%$ pig samples. AMR studies revealed $42 \%$ and $36.58 \%$ E. coli, respectively from chicken and pigs as ESBL producers. Beta lactam genes, $b l a_{T E M}$ and $b l a_{C T X-M}$ were detected, however, the isolates were negative for $b l a_{S H V}$ and $b l a_{O X A}$ genes. About $47.61 \%$ and $46.66 \%$ E. coli of chicken and pigs, respectively showed presence of beta lactam genes. Chicken isolates were resistant to cefixime (96\%), tetracycline (88\%), and ciprofloxacin (94\%). While, pig isolates were resistant to cefazolin $(100 \%)$, ciprofloxacin $(65.85 \%)$ and gentamicin $(51.21 \%)$. High degree of sensitivity was recorded for imipenem and trimethoprim. Multidrug resistant $E$. coli showing resistance to three or more group of antimicrobials were also recorded. This study is significant in the context of AMR highlighting the importance of pigs and chicken in carrying ESBL type E. coli.
\end{abstract}

\section{HIGHLIGHTS}

0 ESBL type of antimicrobial resistance was detected in E. coli isolated from pigs and broilers.

0 bla $a_{C T X-M}$ and $b l a_{T E M}$ genes encoding ESBL resistance were detected.

(0 Multi-drug resistant $E$. coli strains are present in the feces of pigs and broilers.

Keywords: E. coli, beta lactam, ESBL, resistance, pigs, poultry

Escherichia coli (E. coli) is a very diverse and predominant group of bacterial community ubiquitous to animal, human and plant environments. It is often referred as a indicator for fecal contamination in food and water. Simultaneously, it is also considered an indicator of antimicrobial resistance (AMR). Therefore, monitoring of E. coli from diverse sources to explore the epidemiology of AMR is a valuable approach. Antibiotic resistance is a global challenge of recent times and all the major national and international organizations are working together to mitigate this challenge (WHO, 2014). If AMR will continue to spread

How to cite this article: Mahadewaswami, R., Kolhe, R., Bhong, C., Mhase, P., Jadhav, S., Lonkar, V. and Bhave, S. (2021). Characterization of Pig and Poultry Origin Escherichia coli for Beta-lactamase Type Antimicrobial Resistance. J. Anim. Res., 11(04): 619-625. Source of Support: None; Conflict of Interest: None 
at a current pace, it is estimated that AMR will cause approximately 10 million human deaths per annum and $10 \%$ loss in livestock production by 2050 (O’Neill, 2014). Therefore awareness of all the stakeholders on AMR issue and its management at all the portals of spread is mandatory. Ample of studies were conducted at international level on detection AMR in commensal E. coli of human, animals and foods (Pormohammad et al., 2019), however, limited studies are undertaken on its characterization in terms of prevalence of extended spectrum beta lactamases, beta lactam genes and bla $_{C T X-M}$ groups from India (Samanta et al., 2014; Kar et al., 2015; Samanta et al., 2015). Poultry and pigs are considered as the most immediate sources of AMR transmission from animals to humans. Broiler farming is very common in most of the states of India, however pig farming is not very popular except some north eastern and southern states. In this preliminary study, attempts were made to characterize commensal $E$. coli isolated from fecal samples for detection of ESBL production and presence of beta lactam genes.

\section{MATERIALS AND METHODS}

\section{Sampling and bacterial culture}

During this study, a total of 100 fecal samples were collected, 50 samples each from broiler chicken and large white Yorkshire pigs. Chicken samples were collected from a single farm with 6000 broiler birds under intensive farming and pig samples were collected from two different farms (A) and (B). Farm A was having 300 pigs and farm $\mathrm{B}$ was holding 250 pigs. History of antibiotics used at these farms could not be obtained. All the birds and pigs sampled were apparently healthy. Without any specific criteria, random sampling was performed. In case of pigs, 25 samples were collected from each farm. All the samples were labelled and transported under ice to the laboratory and cultured for bacterial growth on the same day of collection. Rectal/ cloacae swabs were enriched in the Enterobacteriacea enrichment broth (EEB, HiMedia Mumbai) for $24 \mathrm{hr}$ at $37^{\circ} \mathrm{C}$. A loop full of enriched culture was inoculated on the EMB agar and after incubation at $37{ }^{\circ} \mathrm{C}$ for $24 \mathrm{hr}$, plates were observed for presumptive colonies. Isolates were further purified on EMB agar and representative 4-5 colonies were further confirmed by staining, morphology and biochemical characteristics namely catalase, oxidase, indole and methyl red, VogesProskauer and citrate utilization as per the Bergey's Manual of Systematic Bacteriology.

\section{Antibiogram}

Phenotypic resistance and sensitivity patterns of E. coli isolated from pigs and broiler birds were recorded against 10 different antimicrobials (HiMedia Laboratories, Mumbai) by Kirby-Bauer method and results were interpreted in accordance to the recommendations of Clinical and Laboratory Standards Institute (CLSI, 2017). All the $E$. coli isolates were further studied for extended spectrum beta lactamase (ESBL) production by disc diffusion synergy test (DDST) in accordance to the CLSI. All the isolates were first subjected for initial screening using five antimicrobial discs namely cefpodoxime $\left(10 \mu \mathrm{g}^{-}\right.$ $\left.{ }^{1}\right)$, ceftazidime $\left(30 \mu \mathrm{g}^{-1}\right)$, aztreonam $\left(30 \mu \mathrm{g}^{-1}\right)$, cefotaxime (30 $\left.\mu \mathrm{g}^{-1}\right)$, ceftriaxone $\left(30 \mu \mathrm{g}^{-1}\right)$. Initial screening was followed by ESBL confirmation using cephalosporin discs alone and cephalosporin discs in combination with ESBL inhibitor clavulanic acid. Antimicrobials used for ESBL confirmation were cefotaxime $\left(30 \mu \mathrm{g}^{-1}\right)$, cefotaxime/clavulanic acid $\left(10 \mu \mathrm{g}^{-1}\right)$, and ceftazidime $\left(30 \mu \mathrm{g}^{-1}\right)$, ceftazidime/clavulanic acid $\left(10 \mu \mathrm{g}^{-1}\right)$. E. coli isolates showing a zone difference of $\geq 5 \mathrm{~mm}$ between cephalosporin alone and cephalosporin in combination with clavulanic acid were confirmed as ESBL producers. For AMR studies, E. coli were enriched overnight at $37^{\circ} \mathrm{C}$ in the Brain Heart Infusion (BHI) broth and streaking was done on the Mueller Hinton Agar (MHA) plates.

\section{Detection of beta-lactamases genes}

All the E. coli strains resistant to ESBL type of AMR were further studied for the presence of four beta lactam genes namely $b l a_{T E M} b l a_{C T X-M} b l a_{S H V}$ and $b l a_{O X A}$ by multiplex PCR assay described previously (Fang et al. 2008). Bacterial DNA was extracted by boiling and snap chilling method. Pure bacterial colony was suspended in $100 \mu$ nuclease free water, boiled for five minutes and immediately snap chilled in crushed ice for one minute. Tubes were centrifuged at $10000 \mathrm{rpm}$ for two minutes and supernatant was used as DNA template. Multiplex PCR was performed in a total volume of $25 \mu \mathrm{l}$ volume containing $12.5 \mu \mathrm{l} 2 \mathrm{x}$ PCR master mix supplied with Taq polymerase, buffer, $\mathrm{MgCl}_{2}$ and dNTPs (HiMedia Laboratories Mumbai); $1 \mu \mathrm{l}$ 
each forward and reverse primers, $2 \mu \mathrm{L}$ DNA template and $2.5 \mu \mathrm{L}$ nuclease free water. Reactions were carried out in the thermal cycler (Veriti ${ }^{\mathrm{TM}}$, Applied Biosystems). Cycling conditions involved, one cycle of initial denaturation $\left(95^{\circ} \mathrm{C} / 15 \mathrm{~min}\right)$ followed by 30 cycles of denaturation $\left(94^{\circ} \mathrm{C} / 30 \mathrm{sec}\right)$, annealing $\left(62^{\circ} \mathrm{C} / 90 \mathrm{sec}\right)$, and extension $\left(72^{\circ} \mathrm{C} / 60 \mathrm{sec}\right)$. Final extension of DNA was achieved at $72^{\circ} \mathrm{C}$ for $10 \mathrm{~min}$. Amplified PCR products were separated in $1.5 \%$ agarose gel electrophoresis stained with ethidium bromide. Primers used for detection of beta lactam genes are presented in Table 1.

\section{RESULTS AND DISCUSSION}

This study was conducted to estimate the prevalence of ESBL producing $E$. coli in the fecal samples of broilers and pigs. Out of 100 fecal samples obtained from broiler birds and pigs, E. coli strains were isolated from 91 samples. Occurrence of E. coli was recorded in $100 \%$ broiler fecal samples and $82 \%$ of the pig fecal samples. E. coli is predominant prototype Gram negative organism of Enterobacteriacea family and it is generally present in the gastrointestinal tract of the mammal, birds and other invertebrates. Therefore, its presence in the fecal matter is not surprising. All the E. coli strains isolated from broiler and pigs were studied for antimicrobial resistance with special reference to ESBL production and beta lactam genes. It was revealed that pigs and poultry origin E. coli are multi-drug resistant strains and ESBL producers. E. coli isolates from broiler birds exhibited maximum resistance to cefazolin (96\%), tetracycline (88\%), and ciprofloxacin (94\%), while pig origin isolates showed higher resistance to cefazolin $(100 \%)$, ampicillin $(73.17 \%)$, ciprofloxacin $(65.85 \%)$, cefixime $(51.21 \%)$ and gentamicin $(51.21 \%)$.
Isolates under study were highly sensitive to imipenem and trimethoprim. Chloramphenicol sensitive (56.09\%) pig isolates were also recorded during the study (Table 2). ESBL producing E. coli were comparatively isolated in high numbers which is indicative of the fact that food animals and poultry are the reservoirs of emerging antimicrobial resistance. Over $30 \%$ of the E. coli from poultry and pigs were ESBL producers. Moreover similar pattern of antimicrobial resistance has also been recorded in the E. coli isolated from poultry and pigs by previous investigators (Miles et al., 2006; Pholwat et al., 2020).

All the ESBL producing strains of E. coli were studied by multiplex PCR for the presence of beta lactam genes. Prevalence of bla $a_{C T X-M}$ and bla $a_{T E M}$ was recorded, however $b l a_{S H V}$ and $b l a_{O X A}$ could not be detected. Prevalence of bla ${ }_{C T X-M}$ was more in broilers $(33.33 \%)$, while bla was detected in higher percentage in pigs. Variations are recorded in the resistance and sensitivity pattern of the E. coli from pigs and broilers (Table $3 \& 4$ ). Multi drug resistant $E$. coli exhibiting resistance to three or more group of antimicrobials has also been recoded $(16.48 \%)$ in this study. Present findings are consistent to previous reports from India. Very high prevalence of ESBL producing $b l a_{C T X-M}$ and bla $a_{T E M}$ positive E. coli in piglets with diarrhea was recorded, wherein samples were collected from eight states of India (Vinodh Kumar et al., 2019). In another study from Mizoram, E. coli from pig feces resistant to ampicillin, tetracycline and trimethoprim were recorded. Similarly E. coli were ESBL type and bla $a_{T E M}$ and $b l a_{C T X-M}$ positivity was recorded in pigs from organized and unorganized farms (Mandakini et al., 2020). Almost similar prevalence of ESBL type E. coli was also reported in the fecal samples of pigs slaughtered in United

Table 1: Oligonucleotide sequences used for detection of beta lactam genes

\begin{tabular}{|c|c|c|c|c|c|}
\hline Sl. No. & $\begin{array}{l}\text { Name of the } \\
\text { primers }\end{array}$ & Oligonucleotide sequence (3'-5') & $\begin{array}{l}\text { Genes } \\
\text { encoded }\end{array}$ & $\begin{array}{l}\text { Product size } \\
\text { in bp }\end{array}$ & Reference \\
\hline 1 & blaSHV-F & CTT TATCGG CCC TCA CTC AA & $b l a_{S H V}$ & 237 & Fang et al. (2008) \\
\hline 2 & blaSHV-R & AGG TGC TCA TCA TGG GAA AG & & & \\
\hline 3 & blaTEM-F & CGC CGC ATA CAC TAT TCT CAG AAT GA & $b l a_{T E M}$ & 445 & \\
\hline 4 & blaTEM-R & ACG CTC ACC GGC TCC AGA TTT AT & & & \\
\hline 5 & blaCTX-M-F & ATG TGC AGY ACC AGT AAR GTK ATG GC & $b l a_{C T X-M}$ & 593 & \\
\hline 6 & blaCTX-M-R & TGG GTR AAR TAR GTS ACC AGA AYC AGC GG & & & \\
\hline 7 & blaOXA-F & ACA CAA TAC ATA TCA ACT TCG C & $b l a_{O X A}$ & 813 & \\
\hline 8 & blaOXA-R & AGT GTG TTT AGA ATG GTG ATC & & & \\
\hline
\end{tabular}


Table 2: Antibiogram and prevalence of $E$. coli isolated from broiler birds and pigs

\begin{tabular}{|c|c|c|c|c|c|c|c|c|c|}
\hline \multirow{3}{*}{ Antimicrobials used } & \multirow{3}{*}{$\begin{array}{l}\text { Concentration } \\
\text { per disc (쓰) }\end{array}$} & \multicolumn{4}{|c|}{ Resistant pattern } & \multicolumn{4}{|c|}{ Sensitive pattern } \\
\hline & & \multicolumn{2}{|c|}{ Broiler birds $(n=50)$} & \multicolumn{2}{|c|}{ Pigs $(n=41)$} & \multicolumn{2}{|c|}{ Broiler birds $(n=50)$} & \multicolumn{2}{|c|}{ Pigs $(n=41)$} \\
\hline & & No & $\%$ & No & $\%$ & No & $\%$ & No & $\%$ \\
\hline Ampicillin (AMP) & 10 & 8 & 16 & 30 & 73.17 & 14 & 28 & 4 & 9.75 \\
\hline Cefazolin (CZ) & 30 & 48 & 96 & 41 & 100 & 0.00 & 0.00 & 0 & 0.00 \\
\hline Cefixime (CFM) & 5 & 12 & 24 & 21 & 51.21 & 26 & 52 & 4 & 9.75 \\
\hline Gentamicin (GNE) & 10 & 14 & 28 & 21 & 51.21 & 14 & 28 & 11 & 26.82 \\
\hline Kanamycin (K) & 30 & 12 & 24 & 8 & 19.51 & 8 & 16 & 4 & 9.75 \\
\hline Tetracycline (TE) & 30 & 44 & 88 & 18 & 43.90 & 1 & 2 & 7 & 17.07 \\
\hline Ciprofloxacin (CIP) & 5 & 47 & 94 & 27 & 65.85 & 1 & 2 & 4 & 9.75 \\
\hline Imipenem (IPM) & 10 & 0.00 & 0.00 & 0.00 & 0.00 & 49 & 98 & 38 & 92.68 \\
\hline Chloramphenicol (C) & 30 & 17 & 34 & 11 & 26.82 & 7 & 14 & 23 & 56.09 \\
\hline Trimethoprim (TR) & 5 & 0.00 & 0.00 & 0.00 & 0.00 & 43 & 86 & 41 & 100 \\
\hline
\end{tabular}

Table 3: Prevalence of ESBL producing E. coli in broiler birds and pigs

\begin{tabular}{lllllllll}
\hline Source & $\begin{array}{l}\text { No of } \\
\text { samples }\end{array}$ & $\begin{array}{l}\text { No of isolates } \\
\text { \& prevalence }\end{array}$ & ESBL strains & $\begin{array}{l}\text { Beta lactam } \\
\text { genes }\end{array}$ & $\boldsymbol{b l a}_{\text {CTX-M }}$ & $\boldsymbol{b l a}_{\text {SHV }}$ & $\boldsymbol{b l a}_{\text {TEM }}$ & $\boldsymbol{b l a}_{\text {OXA }}$ \\
\hline Broiler birds & 50 & $50(100 \%)$ & $21(42 \%)$ & $10(47.61 \%)$ & $7(33.33 \%)$ & 0.00 & $3(14.28 \%)$ & 0.00 \\
Pigs & 50 & $41(82 \%)$ & $15(36.58 \%)$ & $7(46.66 \%)$ & $2(13.33 \%)$ & 0.00 & $5(33.33 \%)$ & 0.00 \\
Total & 100 & $91(91 \%)$ & $36(39.56 \%)$ & $17(47.22 \%)$ & $9(25 \%)$ & 0.00 & $8(22.22 \%)$ & 0.00 \\
\hline
\end{tabular}

Table 4: Most common resistant pattern of ESBL positive E. coli

\begin{tabular}{|c|c|}
\hline Source & ESBL positive strains \\
\hline \multirow[t]{6}{*}{ Broiler birds } & CZ CFM K TE CIP \\
\hline & CZ K TE CIP C \\
\hline & $\mathrm{CZ} \mathrm{TE}$ \\
\hline & CZ TE CIP C \\
\hline & CZ GEN TE CIP \\
\hline & CZ CFM GEN CIP C \\
\hline \multirow[t]{6}{*}{ Pigs } & AMP CZ CFM CIP C \\
\hline & CZ CFM GEN CIP \\
\hline & AMP CZ CFM GEN CIP C \\
\hline & AMP CZ CFM \\
\hline & AMP CZ CFM GEN TE CIP \\
\hline & bla ${ }_{\text {CTXM }}$ positive isolates \\
\hline \multirow[t]{7}{*}{ Broiler birds } & CZ TE CIP C \\
\hline & AMP CZ TE CIP C \\
\hline & CZ CFM TE CIP C \\
\hline & CZ K TE CIP \\
\hline & CZ CFM GEN K TE CIP \\
\hline & CZ TE CIP C \\
\hline & CZ GEN K TE CIP \\
\hline
\end{tabular}




\begin{tabular}{ll} 
Pigs & AMP CZ CIP \\
& CZ GEN TE \\
\hline Broiler birds & CZ CFM K TE CIP \\
& CZ TE \\
Pigs & CZ GEN K TE CIP \\
& AMP CZ CIP \\
& CZ GEN TE \\
& AMP CZ \\
& AMP CZ CFM GEN TE CIP \\
& AMP CZ GEN TE \\
\hline
\end{tabular}

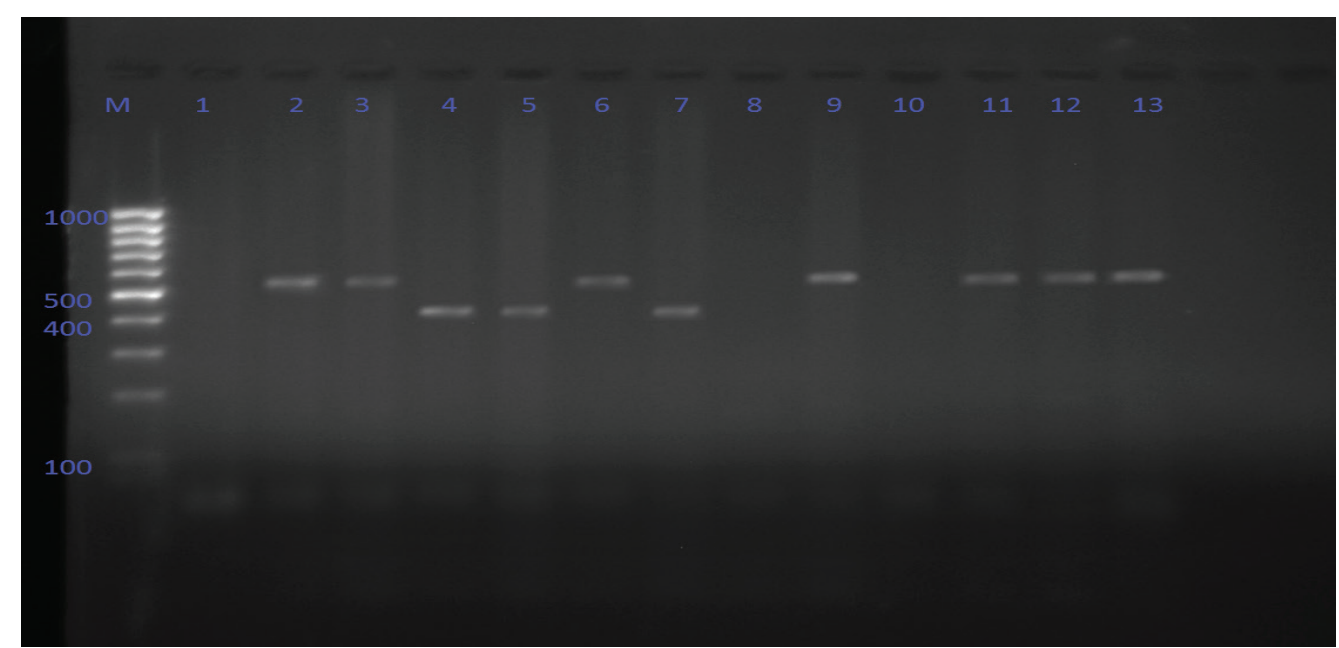

Lanes from left to right - Lane M- 100 bp DNA ladder; Lanes 2,3,6,9,11,12,13 : positive for $b_{l} a_{C T X-M}\left(593\right.$ bp); Lanes 4,5,7: positive for $b_{l a} a_{T E M}$ (445 bp).

Fig. 1: Multiplex PCR for detection of beta lactam genes in broiler origin E. coli.

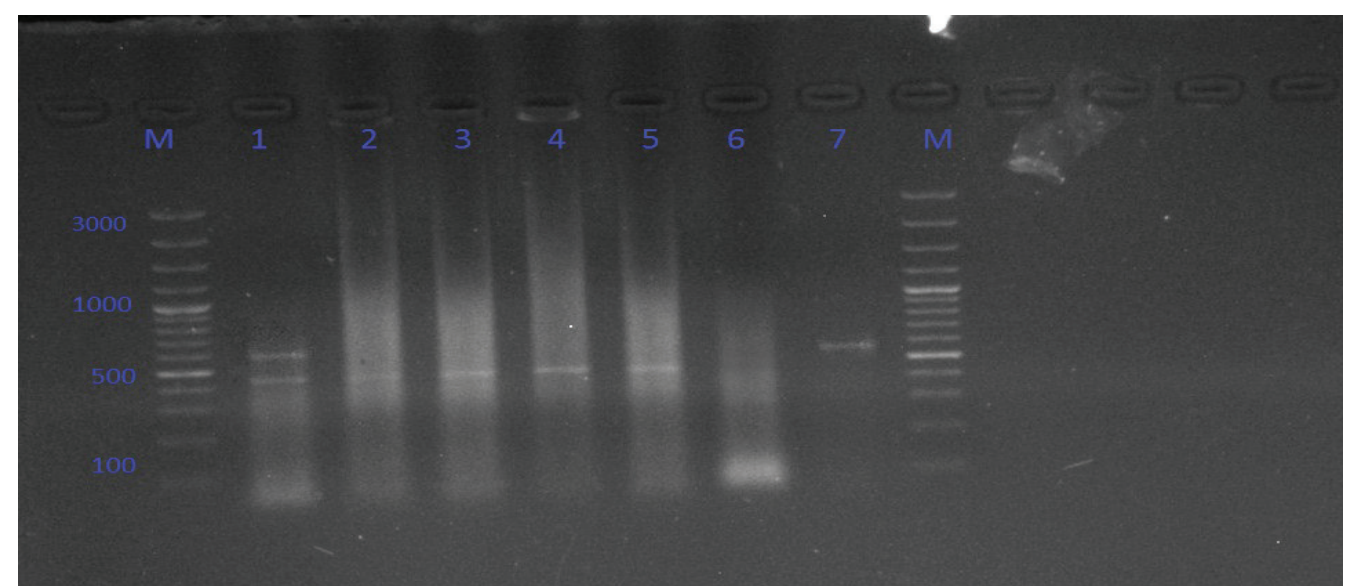

Lanes from left to right - Lane M- $100 \mathrm{bp}$ DNA ladder; Lanes 1,7: positive for $b l a_{C T X-M}(593 \mathrm{bp})$; Lanes 2,3,4,5: positive for bla $_{T E M}(445 \mathrm{bp})$.

Fig. 2: Multiplex PCR for detection of beta lactam genes in pig origin E. coli 
Kingdom, and $C T X-M(22 \%)$ and $S H V(2.2 \%)$ genes were detected (Randall et al., 2014). ESBL and $C T X-M$ positive $E$. coli were also isolated from fecal samples of piglets and farm workers at the organized farms from India (Tamta et al., 2020). ESBL producing E. coli in poultry were also detected by other investigators across the globe and from India. A study from Punjab revealed high prevalence of $E$. coli resistant to ciprofloxacin, tetracycline and ampicillin as well as ESBL producing strains isolated from broilers as compared to layers (Brower et al., 2017). E. coli isolated from healthy chicken gut from Nepal revealed predominance of CTXM-15 ESBL enzyme (Hosuru Subramanya et al., 2020). As recorded in this study, poultry origin E. coli are mainly harbouring $b l a_{C T X-M}$ and $b l a_{T E M}$ genes as recorded by other workers (Girlich et al., 2007; Gundran et al., 2019).

Increasing resistance to beta lactam group of antimicrobials globally in human and animals including poultry is due to their widespread use which has increased selective pressure and diversified antimicrobial resistance mechanisms. ESBL type of bacterial resistance is due to the beta-lactamases hydrolysing the antibacterial activity of penicillins, cephalosporins, and aztreonam, but they are inhibited by clavulanic acid. After the introduction of third generation cephalosporins, resistance in the bacterial species has been recorded to these extended spectrum antimicrobials termed as ESBL resistance. TEM, SHV, $C T X-M$ and $O X A$ are the group of enzymes encoding ESBL type of resistance. $C T X-M$ type of resistance is considered as most frequent and widespread globally in the bacterial population (Paterson and Bonomo, 2005).

\section{CONCLUSION}

Present results reveal the prevalence of $E$. coli harbouring bla $a_{C T X-M}$ and $b l a_{T E M}$ ESBL genotypes in broilers and pigs. The high prevalence of multidrug resistant $E$. coli with coexistence of ESBL genotypes is alarming in the context of AMR and One health. More intensive and integrated AMR surveillance on livestock and poultry is necessary to correlate emerging type of antimicrobial resistance in the food chain.

\section{ACKNOWLEDGMENTS}

Authors are thankful to the Associate Dean KNP College of Veterinary Science, Shirwal for financial support and
In-Charge CIF, KNPCVS Shirwal for providing laboratory facilities for this research.

\section{REFERENCES}

Brower, C.H., Mandal, S., Hayer, S., Sran, M., Zehra, A., Patel, S.J., Kaur, R., Chatterjee, L., Mishra, S., Das, B.R., Singh, P., Singh, R., Gill, J. and Laxminarayan, R. 2017. The Prevalence of Extended-Spectrum Beta-LactamaseProducing multidrug-resistant Escherichia coli in poultry chickens and variation according to farming practices in Punjab, India. Environ. Health Perspect., 125(7): 077015.

Clinical Laboratory Standard Institute (CLSI). 2017. Performance standards for antimicrobial susceptibility testing. $27^{\text {th }} \mathrm{Ed}$., CLSI supplement M100 Clinical and Laboratory Standards Institute, Wayne, PA.

Fang, H., Ataker, F., Hedin, G. and Dornbusch, K. 2008. Molecular epidemiology of extended-spectrum betalactamases among Escherichia coli isolates collected in a Swedish hospital and its associated health care facilities from 2001 to 2006. J. Clin. Microbiol., 46(2): 707-712.

Girlich, D., Poirel, L., Carattoli, A., Kempf, I., Lartigue, M.F., Bertini, A. and Nordmann, P. 2007. Extended-spectrum betalactamase CTX-M-1 in Escherichia coli isolates from healthy poultry in France. Applied Environ. Microbiol., 73(14): 46814685 .

Gundran, R.S., Cardenio, P.A., Villanueva, M.A., Sison, F.B., Benigno, C.C., Kreausukon, K., Pichpol, D. and Punyapornwithaya, V. 2019. Prevalence and distribution of bla ${ }_{\text {CTX-M}}, b_{\text {SHV }}$, bla $_{\text {TEM }}$ genes in extended- spectrum $\beta$ lactamase- producing $E$. coli isolates from broiler farms in the Philippines. BMC Vet. Res., 15(1): 227.

Hosuru Subramanya, S., Bairy, I., Nayak, N., Amberpet, R., Padukone, S., Metok, Y., Bhatta, D.R. and Sathian, B. 2020. Detection and characterization of ESBL-producing Enterobacteriaceae from the gut of healthy chickens, Gallus gallus domesticus in rural Nepal: Dominance of CTX-M15-non-ST131 Escherichia coli clones. PloS One., 15(5): e0227725.

Kar, D., Bandyopadhyay, S., Bhattacharyya, D., Samanta, I., Mahanti, A., Nanda, P.K., Mondal, B., Dandapat, P., Das, A. K., Dutta, T.K., Bandyopadhyay, S. and Singh, R.K. 2015. Molecular and phylogenetic characterization of multidrug resistant extended spectrum beta-lactamase producing Escherichia coli isolated from poultry and cattle in Odisha, India. Infect. Genet. Evol., 29: 82-90.

Mandakini, R., Roychoudhury, P., Subudhi, P.K., Kylla, H., Samanta, I., Bandyopadhayay, S. and Dutta, T.K. 2020. Higher prevalence of multidrug-resistant extended-spectrum $\beta$-lactamases producing Escherichia coli in unorganized 
pig farms compared to organized pig farms in Mizoram, India. Vet. World., 13(12): 2752-2758.

Miles, T.D., McLaughlin, W. and Brown, P.D. 2006. Antimicrobial resistance of Escherichia coli isolates from broiler chickens and humans. BMC Vet. Res., 2: 7.

O'Neill J. 2014. Review on Antimicrobial Resistance: Tackling a crisis for the health and wealth of nations. The Review on Antimicrobial Resistance., December, pp. 1-20.

Paterson, D.L. and Bonomo, R. A. 2005. Extended-spectrum beta-lactamases: a clinical update. Clin. Microbiol. Rev., 18(4): 657-686.

Pholwat, S., Pongpan, T., Chinli, R., Rogawski McQuade, E. T., Thaipisuttikul, I., Ratanakorn, P., Liu, J., Taniuchi, M., Houpt, E.R. and Foongladda, S. 2020. Antimicrobial resistance in swine fecal specimens across different farm management Systems. Front. Microbiol., 11: 1238.

Pormohammad, A., Nasiri, M.J. and Azimi, T. 2019. Prevalence of antibiotic resistance in Escherichia coli strains simultaneously isolated from humans, animals, food, and the environment: a systematic review and meta-analysis. Infect. Drug Res., 12: 1181-1197.

Randall, L.P., Lemma, F., Rogers, J.P., Cheney, T.E., Powell, L.F. and Teale, C.J. 2013. Prevalence of extended-spectrum- $\beta$ lactamase-producing Escherichia coli from pigs at slaughter in the UK in 2013. J. Antimicrob. Chemother, 69(11): 29472950.
Samanta, I., Joardar, S.N., Das, P.K., Sar, T.K., Bandyopadhyay, S., Dutta, T.K. and Sarkar, U. 2014. Prevalence and antibiotic resistance profiles of Salmonella serotypes isolated from backyard poultry flocks in West Bengal, India. J. Appl. Poultry Res., 23(3): 536-545.

Samanta, I., Joardar, S.N., Mahanti, A., Bandyopadhyay, S., Sar, T.K. and Dutta, T.K. 2015. Approaches to characterize extended spectrum beta-lactamase/beta-lactamase producing Escherichia coli in healthy organized vis-a-vis backyard farmed pigs in India. Infect. Genet. Evol., 36: 224-230.

Tamta, S., Kumar, O., Singh, S.V., Pruthvishree, B.S., Karthikeyan, R., Rupner, R., Sinha, D.K. and Singh, B.R. 2020. Antimicrobial resistance pattern of extended-spectrum $\beta$-lactamase-producing Escherichia coli isolated from fecal samples of piglets and pig farm workers of selected organized farms of India. Vet. World., 13(2): 360-363.

VinodhKumar, O.R., Singh, B.R., Sinha, D.K., Pruthvishree, B.S., Tamta, S., Dubal, Z.B., Karthikeyan, R., Rupner, R.N. and Malik, Y.S. 2019. Risk factor analysis, antimicrobial resistance and pathotyping of Escherichia coli associated with pre- and post-weaning piglet diarrhoea in organised farms, India. Epidem. Infect., 147: e174.

World Health Organization. 2014. Antimicrobial resistance: global report on surveillance 2014. Geneva, Switzerland. 
